\title{
Altered Molecular Regionalization and Normal Thalamocortical Connections in Cortex-Specific Pax6 Knock-Out Mice
}

\author{
Maria Carmen Piñon, ${ }^{1 *}$ Tran Cong Tuoc, ${ }^{2,3 *}$ Ruth Ashery-Padan, ${ }^{4}$ Zoltán Molnár, ${ }^{1}$ and Anastassia Stoykova ${ }^{2,3}$ \\ ${ }^{1}$ Department of Physiology, Anatomy, and Genetics, University of Oxford, Oxford OX1 3QX, United Kingdom, ${ }^{2}$ Max Planck Institute for Biophysical \\ Chemistry, 37077 Göttingen, Germany, ${ }^{3}$ Deutsche Forschungsgemeinschaft, Center of Molecular Physiology of the Brain, 37073 Göttingen, Germany, and \\ ${ }^{4}$ Sackler Faculty of Medicine, Department of Human Molecular Genetics and Biochemistry, Tel Aviv University, Tel Aviv 69978, Israel
}

\begin{abstract}
Transcription factor Pax6 exerts a prominent rostrolateral ${ }^{\text {high }}$ to caudomedial ${ }^{\text {low }}$ expression gradient in the cortical progenitors and have been implicated in regulation of area identity in the mammalian cortex. Herein, we analyzed the role of Pax6 in molecular arealization and development of thalamocortical connections in the juvenile cortex-specific conditional Pax6 knock-out mice (Pax6cKO). Using a set of molecular markers of positional identity (Id2, Cadherin6, COUP-TF1, RZR , and EphA7), we show that, in the juvenile Pax6cKO, the relative size of caudal cortical areas (putative visual and somatosensory) are mildly enlarged, whereas the rostral domain (putative motor) is severely reduced. Despite the rostral shift of graded expression of areal markers, the distribution of area-specific thalamocortical and corticofugal projections appear normal in the Pax $6 c K O$. This indicates that change of the size of cortical areas is not accompanied by a change in cortical identity. We show furthermore that, despite a severe depletion of supragranular cortical layers and accumulation of cells along the pallial-subpallial boundary, thalamocortical fibers establish a periphery-related pattern of the somatosensory cortex in normal position in Pax6cKO. Our findings indicate that Pax6 expression gradients in cortical progenitors do not directly impart thalamocortical or corticofugal areal identity.
\end{abstract}

Key words: Pax6; cortex; arealization; thalamus; connections; mouse

\section{Introduction}

Cortical circuitry is established by contributions of both molecular gradients encoded on the cortical progenitors and signals from thalamocortical axons (TCAs) (Rakic, 1988; O’Leary, 1989; Price et al., 2006; Dehay and Kennedy, 2007). A current view states that forebrain inductive centers control graded expression of a number of transcription factors (TFs) such as Emx2, COUPTF1, Pax6, and SP8 in the cortical progenitors producing a rough protomap (O'Leary and Nakagawa, 2002; Grove and FukuchiShimogori, 2003; Sur and Rubenstein, 2005; Rash and Grove, 2006; Mallamaci and Stoykova, 2007). The parallel change of gene expression gradients and TCA areal targeting has been dem-

Received June 6, 2008; revised July 10, 2008; accepted July 14, 2008.

This work was supported by Max Plack Gesellschaft, the Deutsche Forschungsgemeinschaft-Center of Molecular Physiology of the Brain (T.C.T., A.S.), and Medical Research Council of the United Kingdom (Z.M., M.C.P.). R.A.-P. was supported by Israel Science Foundation, German Israeli Foundation, and Adrenomyeloneuropathy Foundation. We thank K. Jones and J. Gorski for providing the Emx1Cre mouse line. Thanks are due to M. Daniel and S. Eckert for outstanding technical assistance. We thank F. Guillemot, M. Hibi, M. Lie, J. Liu, M. Price, T. Rabbitts, V. Tarabykin, S Tole, and J. Rubenstein for gifts of plasmid DNA. We are very grateful to Jamin DeProto, Theresa L. Furey, and Rebecca Chodroff for critical comments on this manuscript.

${ }^{*}$ M.C.P. and T.C.T. contributed equally to this work.

Correspondence should be addressed to either of the following: Anastassia Stoykova, Department of Molecular Cell Biology, Max Planck Institute for Biophysical Chemistry, Am Fassberg 11, 37077 Göttingen, Germany, E-mail: astoyko@gwdg.de; or Zoltán Molnár Department of Physiology, Anatomy, and Genetics, University of 0xford, 0xford 0X130X, UK, E-mail:zoltan.molnar@dpag.ox.ac.uk.

D0I:10.1523/JNEUROSCI.2565-08.2008

Copyright $\odot 2008$ Society for Neuroscience $\quad 0270-6474 / 08 / 288724-11 \$ 15.00 / 0$ onstrated in various mutants. The homeodomain TF Emx2, expressed in a caudomedial ${ }^{\text {high }}$ to rostrolateral ${ }^{\text {low }}$ gradient, plays an important role in promoting caudomedial fates (O'Leary et al., 1994). By suppressing rostral cortical areal fate and controlling TCA targeting, COUP-TF1 plays a crucial integrative role in coordination of the early molecular patterning, neurogenesis, and laminar fate specification (Armentano et al., 2007; Faedo et al., 2008). Although numerous studies suggest close interactions between early molecular gradients and area-specific thalamic innervation, there are convincing examples for their relative independence. Normal embryonic cortical gradients of gene expression were observed in the absence of thalamic innervation in the $G b \times 2$ and Mash1 knock-out (KO) mice (Miyashita-Lin et al., 1999; Nakagawa et al., 1999). Moreover, shifted targeting of TCAs had no effect on embryonic cortical gene expression pattern in the Ebf1 and Dlx1/2 double knock-out mice (Garel et al., 2003).

The role of TF Pax6 in cortical arealization is not yet fully established. Pax6 is expressed in a rostrolateral ${ }^{\text {high }}$ to caudomedial $^{\text {low }}$ gradient in the developing cortex. The early expression of Pax6 in the dorsal part of the cortical primordium is essential for normal dorsoventral and anteroposterior patterning of the entire telencephalon (Stoykova et al., 2000; Toresson et al., 2000; Yun et al., 2001; Kroll and O'Leary, 2005). In the prenatal cortex of homozygous Pax6 mutants (Sey/Sey), rostrolateral areas are reduced and caudomedial areas are expanded (Bishop et al., 2000, 2002; Muzio et al., 2002), suggesting that Pax6 might confer a 
rostrolateral/ventrodorsal cortical identity. The impact of an altered cortical Pax6 expression on thalamocortical targeting could not be studied in the Pax 6 mutants because the TCAs are unable to extend beyond the pallial-subpallial border (PSPB) (Hevner et al., 2002; Jones et al., 2002). Additionally, Pax6 homozygous mutants show severe diencephalic dysgenesis, lack olfactory bulbs, and die at birth, before completion of neuronal migration and cortical area specification (Hill et al., 1991; Stoykova et al., 1996; Warren and Price, 1997). Thus, the involvement of Pax6 in acquisition of cortical area identity is still insufficiently clarified. In fact, overexpression of Pax6 was shown to have little effect on areal targeting of TCAs (Manuel et al., 2007).

To gain a deeper insight into the role of Pax6 in cortical arealization and thalamocortical targeting, we generated conditional cortex-specific Pax 6 knock-out mice that reach adulthood. Our findings indicate that Pax6 expression gradients in cortical progenitors do not directly impart thalamocortical or corticofugal areal identity.

\section{Materials and Methods}

Animals. To inactivate Pax6 specifically in cortical progenitors, we used transgenic mice with a floxed Pax6 allele (Ashery-Padan et al., 2000) and the Emx1 $1^{I R E S-C r e}$ mouse lines (Gorski et al., 2002). Mice were maintained in a C57BL6/J background and handled in accordance with the German Animal Protection Law. Female homozygous Pax6 floxed animals $\left(\operatorname{Pax} 6^{f l f l}\right)$ and male heterozygous mice $\operatorname{Pax}^{f l /+}$; Emx $1^{I R E S-C r e}$ were crossed to produce $P a x \sigma^{f l f l} ; E m x 1^{I R E S-C r e}$ mutant progeny, named thereafter Pax6cKO. Heterozygous $P a x \sigma^{f l /+}$ or wild-type (WT) animals were used as controls.

In situ hybridization assays and morphometry. In situ hybridization was performed as described by Stoykova and Gruss (1994) using ${ }^{35}$ S-labeled riboprobes on paraffin sections from postnatal 10 (P10) brains of both genotypes. High-quality images were obtained after exposure of the sections to $x$-ray films. The dimensions of distinct cortical domains (expressing corresponding areal markers) were determined from those images. These measurements were used to estimate the proportional areal length, defined as the ratio of the length of each studied domain (revealed through the areal restricted expression of selected markers as described in Results) to the total length of the neocortex (NCX) (between the rostral and caudal pole) in the mutant and control animals. The analyzed data are from two independent experiments. Results are presented as means $\pm \mathrm{SD}$; the number of experiments $(n)$ and $p$ values are indicated in the figure legends. Statistical differences were evaluated using two-tailed, unpaired Student's $t$ tests. The proportional ratios of each domain in the control and mutant cortex were calculated and, together with data for $n$ values, are presented in Tables $1-3$ and supplemental Table $1, A$ and $B$ (available at www.jneurosci.org as supplemental material).

Axonal tracing with carbocyanine dyes. Animals at P1, P2, P3, P10, and P12 were deeply anesthetized by an intraperitoneal injection of sodium pentobarbital ( $50 \mathrm{mg} / \mathrm{kg}$ ), perfused with $4 \%$ paraformaldehyde (in $0.1 \mathrm{M}$ phosphate buffer, $\mathrm{pH}$ 7.3), and had their brain removed from the skull. Forty-six pairs of $\mathrm{P} a x 6 c \mathrm{KO}$ and wild-type cerebral hemispheres between P1 and P12 were used for tracing connectivity between the thalamus and cortex (supplemental Table 2 with the numbers used for various paradigms, available at www.jneurosci.org as supplemental material). Both hemispheres were used, and more than one tracer was placed in the same brain from the same animal. Single crystals of 1,1-dioctadecyl-3,3,3',3'tetramethyl-indocarbocyanine perchlorate (DiI) (Invitrogen) and of [4-(4-(dihexadecylamino)styryl)- $N$-methylpyridium iodide (DiA) (Invitrogen) were placed with a fine tungsten wire into the motor (VA), somatosensory (VB), and visual (dLGN) thalamic nuclei or in the motor $(\mathrm{M})$, somatosensory (SS), and visual (Vi) cortices under a dissecting microscope (Molnár et al., 1998). The brains were photographed to document the injection sites. After $3-4$ weeks, incubating at $37^{\circ} \mathrm{C}$ to allow the transport of the dye, the tissue was embedded in $4 \%$ low-melting agarose (Sigma) and sectioned at $50 \mu \mathrm{m}$ in coronal or sagittal plane using a Vibroslicer (VT1000S; Leica). To visualize the gross morphology, the sections were counterstained with bisbenzimide Hoechst trihydrochloride $(2.5 \mu \mathrm{g} / \mathrm{ml}$ PBS; Sigma-Aldrich). Sections were coverslipped using DakoCytomation medium and analyzed with a fluorescent microscope (Leica DMR), and true color images were captured using a Leica DC 500 digital camera.

Cytochrome-oxidase staining. Brains of Pax $6 \mathrm{cKO}$ and control animals at ages P9-P10 were cryoprotected with sucrose $30 \%$ in phosphate buffer. The cerebral cortex was flattened and sectioned tangentially at 50 $\mu \mathrm{m}$ using a sliding microtome (Microm HM400). The sections were processed for cytochrome-oxidase histochemistry according to WongRiley (1979). Images were captured using a Leica DC 500 digital camera, and the barrel field was reconstructed for each cerebral hemisphere using adjacent sections. The distance from the rostral pole to the center of the barrel field, as well as its proportion in relation to the total distance between the rostral and caudal pole, was calculated for $\mathrm{KO}$ and control brains (see Fig. 7). Results are presented as means \pm SD; the number of cerebral hemispheres $(n)$ and $p$ values are indicated in the figure legends. Statistical differences were evaluated using two-tailed, unpaired Student's $t$ tests.

Quantitative reverse transcription-PCR. Total RNA was extracted using RNeasy kits (Qiagen), treated with DNase I, and quantified by optical density. The quantitative reverse transcription (qRT)-PCR analyses were performed using the QuantiTect Rev Transcription and QuantiTect SYBR Green PCR kit (Qiagen) with qRT-PCR Mastercycler (Eppendorf) according to kit protocols. The ratio between the expression level of target molecules and the reference molecule (housekeeping gene 18S) was determined with a relative quantification analysis. Primers used for qRT-PCR are shown in supplemental Table 3 (available at www. jneurosci.org as supplemental material).

\section{Results}

\section{Conditional inactivation of Pax6 in cortical progenitors}

In the $E m x 1^{I R E S-C r e}$ mice, the Cre recombinase sequence was included into the 3' untranslated region of the Emxl gene, whose expression is restricted to the embryonic pallium (Gorski et al., 2002). The Cre-mediated excision by Emx1 $1^{\text {IRES-Cre }}$ of floxed reporter allele (Gorski et al., 2002), floxed Numb (Li et al., 2003), and floxed COUP-TF1 alleles (Armentano et al., 2007) starts at embryonic day 9.5 (E9.5) in progenitors of the medial pallidum, reaching full recombination at E12.5 of almost all proliferating and postmitotic cells of the entire pallium.

To test the efficiency of the Cre-mediated recombination of the Pax6 ${ }^{\text {flox }}$ allele, cortices of E12.5 Pax $6^{f l f l}$; Emx $1^{\text {IRES-Cre or }}$ $\mathrm{Pax}^{f l /+}$; Emx $1^{I R E S-C r e}$ allele were isolated and analyzed by PCR with three specific oligonucleotide primers, allowing the identification of the floxed (400 bp), WT (300 bp), or the deletion (700 bp) fragment (Fig. 1A). RT-PCR analysis of RNA isolated from mutant cortex and control $\left(\operatorname{Pax}^{f l / f l}\right)$ animals confirmed the deletion of exons 5 and 6 (Fig. $1 B$ ). Western blot analysis of extracted proteins from E12.5 cortices of both genotypes revealed an extremely low level of Pax6 protein in Pax6 $6^{f l / f l} ; E m x 1^{I R E S-C r e}$ pallium (Fig. $1 B$ ). Results from q-PCR assays confirmed that the residual Pax6 expression in the Pax6cKO cortex is $<10 \%$ of the control samples $(8 \pm 3.5 \%)$. Staining for calretinin antibody of E15.5 cortical sections revealed presence of only few cells at the presumptive position of the subplate (data not shown). The generated $P a x 6 c K O$ are healthy, fertile, and reach adulthood without any major pathological symptoms.

\section{Cortical defects in the juvenile Pax6cKO mice}

We first examined the gross morphology of $\mathrm{Pax} 6 \mathrm{cKO}$ brains from $\mathrm{P} 1$ to P10, which revealed the presence of accumulating cells in the white matter and along the PSPB extending from the cortical intermediate zone to beneath the lateral cortex and amygdala in all animals examined (Fig. $2 B, D$, arrowheads). This cell mass is 
less preeminent than the one observed in the Small eye (Sey/Sey) mutant mice (Jones et al., 2002) and curiously does not hamper the thalamocortical axons traveling throughout this region (see Figs. 3, 5). The corpus callosum is underdeveloped and less compact, and the anterior commissure was missing or primarily diminished (data not shown). In the juvenile mutant brain, the overall cortical thickness is reduced and the normal layering is severely disrupted. The large reduction in the upper cortical layers (L4-L2) is becoming very apparent in the adult Pax6cKO cortex. Based on size and packing density of the adult Pax6cKO cortex, no real barrels were seen (data not shown). The use of single crystals of the fluorescent carbocyanine DiI and DiA were placed in multiple nuclei of the thalamus (VB, dLGN, and VA), and the trajectories of the thalamic axons were followed to the cortex. We observed that, despite the severe depletion of layer 4 and the supragranular layers, thalamocortical projections from the $\mathrm{VB}$ reach and invade SS cortex, branches, and arborizes above the preserved layer 5 by P3 (Fig. 3D), and, although not so clear as in the control, they cluster by P10, assuming a somewhat less defined but still distinct periphery related pattern in the SS cortex of the Pax6cKO (Fig. $3 H$ ).

\section{Alteration of areal patterns of gene expression in the neocortex of Pax6cKO mutant}

The fact that TCA show normal ingrowth in the postnatal Pax $6 c K O$ cortex and the thalamus of the $P a x 6 c K O$ is not affected gives us the unique opportunity to directly examine whether Pax6 function in the cortex is intrinsically required to the establishment of area identity. In contrast to Sey/ Sey mutants that lack olfactory bulbs, possibly worsening the forebrain defects, the gross morphology of these structures seems to be preserved in Pax $6 \mathrm{cKO}$.

A number of molecular determinants were reported to exert regionalized expression respecting assumed borders between adjacent cortical domains (Miyashita-Lin et al., 1999). However, the apparent dysgenesis of the upper cortical layers especially prominent in the rostral Pax6cKO cortex imposes some limitations in the choice of the available regional markers. We performed in situ hybridization analyses applying sets of selected markers on matched sagittal sections from the Pax6cKO and control brains at stage P10 at eight lateral-to-medial levels (indicated in the schema in Fig. $4 F$ ). To determine changes in the relative length of the $\mathrm{Vi}$, occipital (Occi) plus parietal (Par), and frontoorbital (FrO) plus $\mathrm{M}$ areas, we performed in situ hybridization assays applying the probes for $I d 2$, Cadherin 6 (Cad6), $R Z R \beta$, and COUP-TF1 on medial sagittal sections at three levels (levels 3-5 in schema in Fig. 4F). At postnatal stage P6-P7, the highest caudal expression of both the transcription factor Id2 ( $I d b 2$; Mouse Genome Informatics) in layer 5 and the retinoid receptor $R Z R \beta$ (Rorb; Mouse Genome Informatics) in layer 4 is confined to the presumptive Vi area of the neocortex (NCX) (Huffman et al.,
B
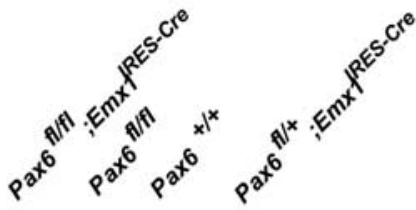
$300 \mathrm{bp}$ $\rightarrow 4 \leftarrow 5-6 \rightarrow 7$ $400 \mathrm{bp}$ : LoxP site $\underset{700 \text { bp }}{\rightarrow} \underset{\text { Primer } 3}{\rightarrow}:$ : Primer 700 bp

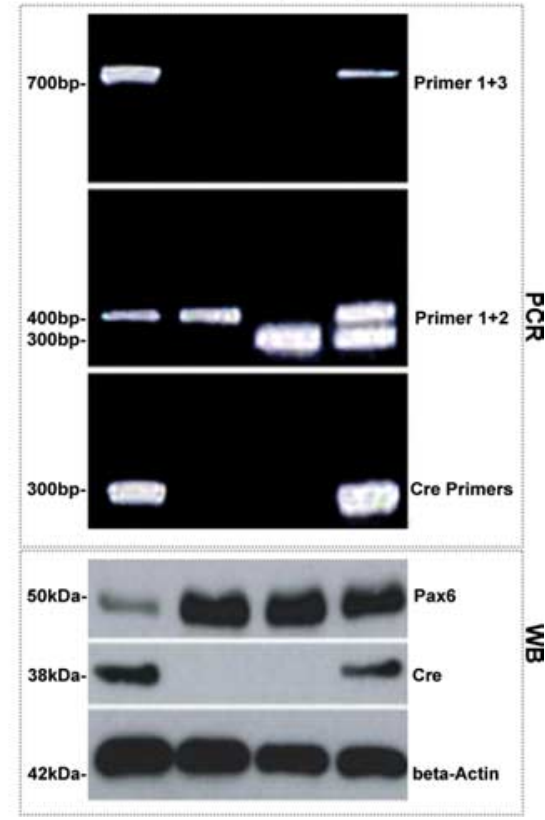

ङ

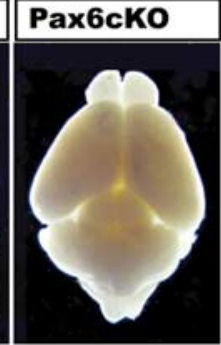

Figure 1. Targeted inactivation of Pax 6 in dorsal telencephalon. $A$, The scheme represents the targeted insertion of LoxP sites Pax 6 gene (Ashery-Padan et al., 2000). The genomic locations of the used primers for genotyping are also shown. In the 政 Pax ${ }^{f / f t}$ allele is proven by PCRs with combinations of primers as indicated in $\boldsymbol{A}$ and DNA samples isolated from E12.5 cortices of

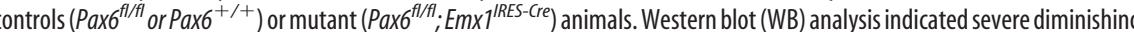
of Pax6 protein level in the mutant cortex (lane 1) compared with controls (lanes 2, 3). C, The pictures illustrate a substantial reduction of the Pax6cKO cortex at postnatal stage P14.

2004; Armentano et al., 2007). The Vi domain is delineated as well by the highest caudalmost expression of both the orphan nuclear receptor COUP-TF1 in layer 4 (Liu et al., 2000) and the adhesive molecule Cad6 in the upper cortical layers (Fig. 4B) (supplemental Fig. $1 B$, available at www.jneurosci.org as supplemental material). The ratios between the length of the strongest caudal expression domain of Id2, Cad6, COUP-TF1, and RZR $\beta$ versus the entire length of the NCX in each genotype were measured for each applied marker that showed a remarkable consistency at all three studied levels (Table 1). Comparison of the averaged relative ratios revealed that the $\mathrm{Vi}$ area is expanded in the Pax6cKO cortex (mutant, $0.3 \pm 0.03, n=16$; control, $0.2 \pm$ $0.05, n=22 ; p<0.01$ ) (Table 1 ), whereas the frontoorbital/ motor cortex domain is severely diminished. Estimated on the basis of the expression of $I d 2, C d h 6$, and COUP-TF1, the relative length of occipital plus parietal cortex is significantly increased in Pax6cKO $(0.84 \pm 0.06, n=12)$ compared with the control $(0.67 \pm 0.06, p<0.001)$. The relative length of the caudal cortex (up to border ii) (Rubenstein et al., 1999) is significantly increased in the mutant $(0.49 \pm 0.04, n=6)$ compared with the control $(0.36 \pm 0.06 \%, p<0.002)$. In contrast, the proportional length of the frontoorbital cortex is significantly decreased in the Pax6cKO $(0.15 \pm 0.02, n=15, p<0.0001)$ compared with the control $(0.33 \pm 0.04)$.

In the neonate mouse cortex, the rostral limit of the strong expression of $I d 2$ in layer 5 and the expression of Cad6 and 


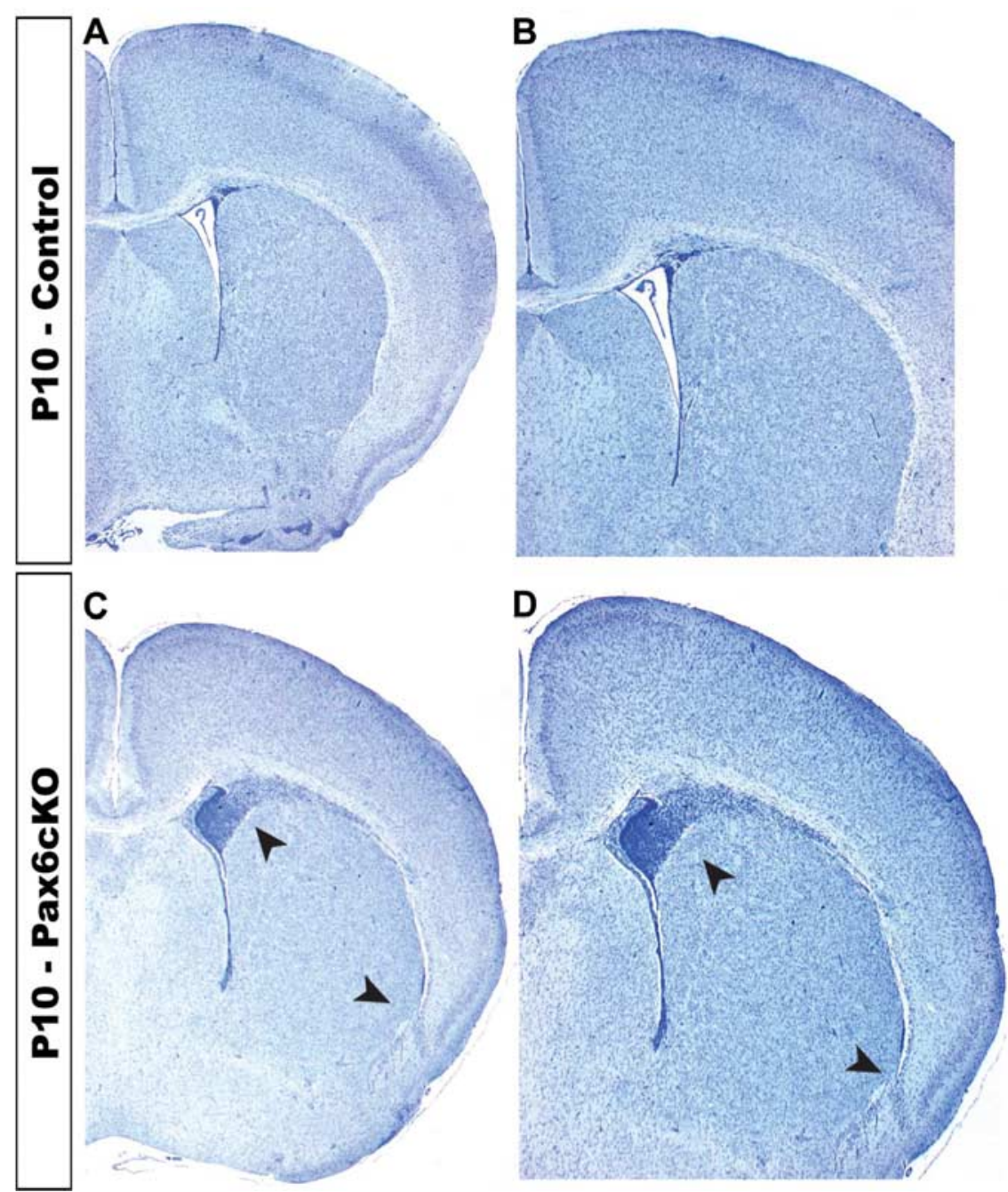

Figure 2. Abnormalities of the juvenile Pax6cK0 brain revealed by Nissl staining. Coronal sections from P10 control and mutant brains stained for cresyl violet. $\boldsymbol{B}$ and $\boldsymbol{D}$ are enlarged views of $\boldsymbol{A}$ and $\boldsymbol{C}$. The arrowheads in $\boldsymbol{C}$ and $\boldsymbol{D}$ point to the defects observed in the brain of Pax6cKO: shorter lateral wings of corpus callosum, reflecting medial to lateral shortage of the mutant neocortex and presence of dense cell masses at the corticostriatal junction, extending from the intermediate zone of the cortex to beneath the lateral cortex and amygdala (ventral arrowhead). We can also notice that there are no clear borders to define layers, and the upper cortical layers $(\mathrm{L} 4, \mathrm{~L} 3, \mathrm{~L} 2)$ are almost completely diminished in the mutant neocortex. We could not observe barrel pattern in the mutant.

COUP-TF1 in the lower layers or layer 4, respectively, demarcates the transition from somatosensory to motor regions (the SS/M boundary as suggested by Rubenstein et al., 1999; Liu et al., 2000; Bishop et al., 2002). Estimated on the basis of these expression patterns, the averaged relative length of Occi plus Par cortex in the mutant is also increased (mutant, $0.84 \pm 0.06, n=11$; control, $0.67 \pm 0.06, n=14 ; p<0.001$ ) (Table 2, Fig. 4). Together, these results indicate that $\mathrm{Vi}$, Occi plus Par domains are rostrally expanded to a similar extent, thus shifting slightly anteriorly the SS/M boundary in the Pax6cKO. We also studied the expression pattern of EphA7, which encodes a receptor protein kinase involved in axonal guidance (Mori et al., 1995) and demarcates another boundary within the SS domain (border ii) (Miyashita-Lin et al., 1999). Compared with the controls, the relative length of this caudal neocortical domain (incorporating the Vi and a part of the Par cortex) showed as well a mild increase in the Pax6cKO cortex (mutant, $0.49 \pm 0.04, n=6$; control, $0.36 \pm 0.06, n=6 ; p<0.002$ ) (Table 2, Fig. 4). In addition, we investigated whether the location and the size of the SS area were affected in the Pax6cKO cortex by using histochemistry for cytochrome-oxidase in flat-mount preparation. As shown in Figure 7 , although reduced in size and not so well defined as in the control, the barrel field pattern can be identified in the SS cortex of the Pax6cKO brain as revealed by the histochemistry for cytochrome-oxidase, and it is centered at a similar position in the cerebral hemisphere as in the control (Fig. 7).

A characteristic feature of molecular patterning of the FrO and $\mathrm{M}$ cortex is the extremely faint expression of $I d 2$ in layer 5 and Cad6 in the low cortical layers, respectively, and the faint diffuse expression of EphA7 in the entire depth of the FrO/M domains (Rubenstein et al., 1999; Garel et al., 2003). Based on the average values of the expression characteristics of these three markers, the $\mathrm{FrO} / \mathrm{M}$ cortex in the control animals represents approximately one-third of the cortex $(0.33 \pm 0.04, n=$ $15)$, whereas in the $P a x 6 c K O$ it represents only one-seventh $(0.15 \pm 0.02, n=15 ; p<$ 0.0001 ) (Table 3, Fig. 4), indicating a severe diminishing of the rostral NCX in the Pax6-deficient animals. Thus, in accordance with previous data for Small eye (Bishop et al., 2002, 2003), Pax6cKO also exhibit a reduction of the $\mathrm{FrO} / \mathrm{M}$ cortex and a complimentary expansion of the regionalized expression of caudal cortical markers.

It is possible, however, that the severe shrinkage of the $\mathrm{FrO} / \mathrm{M}$ area in the Pax $6 c K O$ contributes substantially for the detected increase of the proportional length of the caudal NCX domains. To diminish the contribution of the size of the FrO/M area to the NCX length, we examined the expression of Id2, Cad6, and Cadherin 8 (Cad8) (Bishop et al., 2002) on lateralmost sagittal sections that included exclusively Occi, Par, and part of the basolateral cortex (levels 1, 2 in the schema of Fig. $4 F$ ). Notably, no significant differences were observed in the proportional length of the presumptive Vi domain in both genotypes in these comparisons (supplemental Table $1 A$, available at www.jneurosci.org as supplemental material). Together, these findings suggest that the detected rostral shift of the expression domains of caudal areal markers in the Pax6cKO cortex is a consequence of the severely diminished size of the FrO/M areas in the mutant.

We have shown previously that the expression domain of $W n t 3 a$, a secreted factor that controls progenitor proliferation, is ectopically expanded from medial into the lateral pallium in the cortical primordium of E11.0 Sey/Sey embryos (Muzio et al., 2002). In an attempt to estimate pattern defects in medial cortical domains, we determined the expression of $I d 2$ shown to have specifically strong expression in the upper layers of the cingulate and retrosplenial cortex (Rubenstein et al., 1999). Because of the abrogated upper layers in the rostral cortex of the Pax $6 c K O$, we measured the relative length of the retrosplenial cortex only, using sagittal sections at medialmost levels in which the contribu- 


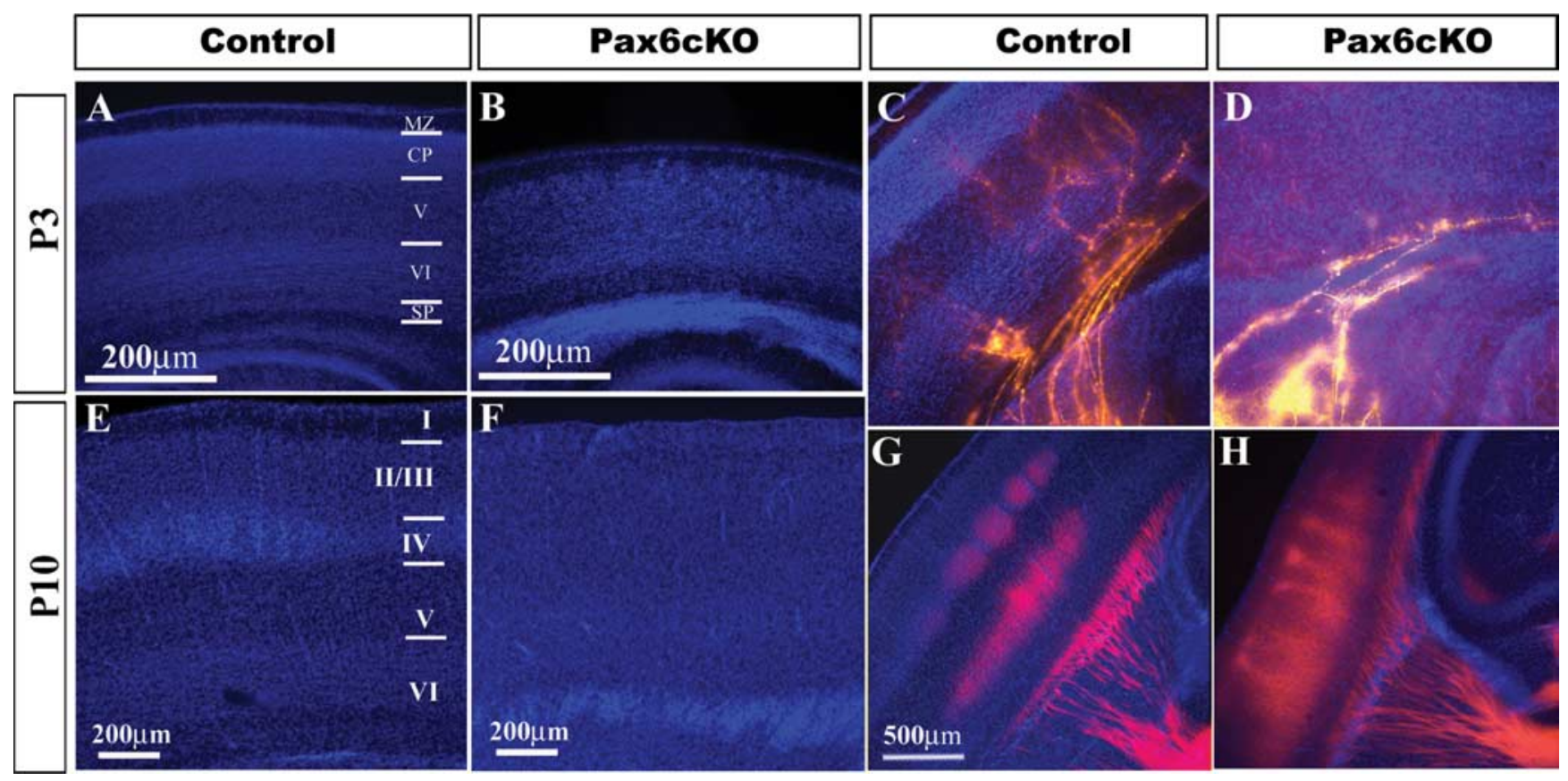

Figure 3. Normal ingrowth of thalamocortical fibers into the abnormal juvenile Pax6cKO cortex. Coronal sections of the cerebral cortex from the control and Pax6cKO at P3 (A-D) and P10 (E-H) stained for bisbenzimide and thalamic axons labeled with Dil from VB $(P 3, C, D ; P 10, G, H)$. In the Pax 6 cKO cortex, the layers are poorly defined and the supragranular layers are almost missing when compared with the control. The defects especially in superficial layer formation can be detected on early postnatal stages, but they become more apparent as the cortex develops. Periphery-related pattern was observed in P10 mutant and control but less defined in the Pax6cKO.C, D, G, H, Carbocyanine dye tracing from dorsal thalamus revealed fibers crossing the pallial-subpallial boundary in normal fascicles and entering the cortex despite the accumulation of cells along that region. The drastic reduction of the supragranular layers had no obvious effect on the thalamic fiber ingrowth into the cortex. Scale bars, $200 \mu \mathrm{m}$. MZ, Marginal zone; (P, cortical plate; SP, subplate.

tion of the $\mathrm{FrO} / \mathrm{M}$ areas is minimal (levels $6-8$ in the scheme in Fig. $4 F$ ). Notably, the domain of strongest superficial expression of $I d 2$ in the caudomedial cortex is proportionally larger in Pax6cKO compared with the controls (mutant, $0.66 \pm 0.03, n=$ 6; control, $0.5 \pm 0.05 ; p<0.00006$ ) (supplemental Table $1 B$, available at www.jneurosci.org as supplemental material). Together, these results strongly suggest that, when Pax6 is not functional, an early pattern defect in medial cortical primordium leads to expansion of the caudomedial cortical areas, most probably resulting from region-specific enhanced cell growth.

\section{Normal thalamocortical connections in Pax6cKO brain}

To directly assess the area identity in the Pax $6 c K O$, we traced TCA connections using anterograde and retrograde labeling with carbocyanine dyes (DiI and DiA) (Figs. 5, 6). Despite the detected alterations in the expression of area-specific markers, thalamic fibers had no change in their areal targeting to putative motor, somatosensory, or visual cortical areas. TCA projections originating from VA, VB, and dLGN correctly targeted cortical areas from the ages of P1-P10. Groups of back-labeled thalamic cells were situated in corresponding position in the KO and WT after DiI and DiA placement in the putative motor, somatosensory, or visual cortices (Fig. 6). These results indicate that, in the Pax $6 c K O$, the topographic organization of the thalamocortical connections is preserved. Furthermore, the axonal trajectories from the putative motor and somatosensory cortices toward the spinal cord and additional targets in basal pons are preserved and the overall distribution of the corticothalamic fibers (CTA) seems unaltered (see Fig. 8). The apparent labeled projections from different cortical areas descended through the intermediate zone in an organized manner in a very similar topographic order. The labeled fiber bundles showed similar patterns (Fig. 5). The position of back-labeled thalamic cells was also very similar in the
Pax6cKO and control. The thalamocortical connectivity was investigated at early stages of P1-P3, as well as at later stages of $\mathrm{P} 9-\mathrm{P} 12$, in which similar results were obtained. Beginning at P1, the correct thalamocortical connectivity between the putative somatosensory and visual domains was established in the Pax6cKO. Back-labeled cells in the VB and dLGN thalamic nuclei were observed after placements of DiI and DiA in the somatosensory and visual cortices at P1-P3, as well as P10 (Fig. 6).

We used additional carbocyanine dye tracing to study thalamocortical fiber entry and branching in the Pax6cKO cortex. After placement of DiI crystals in the VB complex of thalamus at various ages (P1-P10), the thalamic axons entered the cortex and they formed branches. From P10, the thalamic axons had apparent clusters of labeled terminals in the residual L4 of the barrel field of SS in the mutant, although layer 4 has not been entirely differentiated, as in the control animals. These findings indicate that, despite the observed caudalization of the molecular properties of the cortex, the area-specific thalamic innervation and the cortical module arrangement is unaltered in Pax6cKO. The cytochrome-oxidase stain is more suited to study the position of the periphery-related patterning of thalamic axons rather than the barrel cytoarchitecture that can be revealed by Nissl or bisbenzimide staining (López-Bendito and Molnár, 2003). Despite the clear presence of a cytochrome-oxidase staining pattern in the somatosensory cortex (Fig. 7), we failed to detect barrels on Nisslor bisbenzimide-stained sections of $\mathrm{Pax} 6 c \mathrm{KO}$ cortices at any age, including the adults (Figs. 2, 3 and data not shown). Although the individual clusters of thalamic axons are smaller and less well defined, they clearly assume a periphery-related pattern at normal positions (Fig. 7). This finding suggests that the thalamic projections can assume this characteristic pattern in a cortex in which layer 4 and the supragranular layers are severely depleted and the molecular arealization is drastically altered. 

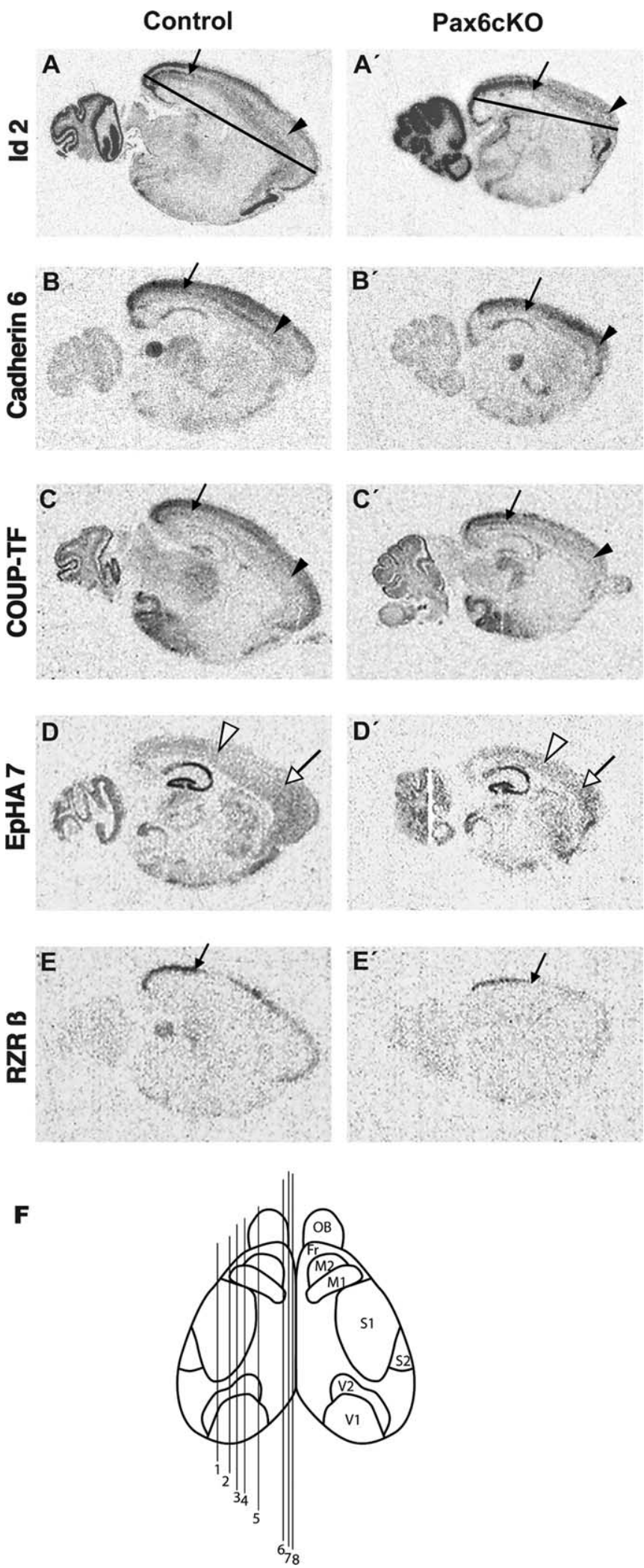

Figure 4. Area patterns of gene expression in the neocortex of Pax6cKO. In situ hybridizations were done on mediosagittal sections from control $(\boldsymbol{A}-\boldsymbol{E})$ and Pax6cKO $\left(\boldsymbol{A}^{\prime}-\boldsymbol{E}^{\prime}\right)$ P10 brains at eight levels (indicated in $\boldsymbol{F}$ ), using ${ }^{35}$ S-labeled riboprobes for different areal markers as indicated. Shown are representative pictures from scanned autoradiograms of hybridized sections (approximately at level 4). The arrows mark the limit of the highest expression in the presumptive visual area of $/ d 2$ in layer $5(\boldsymbol{A}$, $\left.\boldsymbol{A}^{\prime}\right)$, Cadherin $6\left(\boldsymbol{B}, \boldsymbol{B}^{\prime}\right)$ in the upper layers, COUP-TF7 $\left(\boldsymbol{C}, \boldsymbol{C}^{\prime}\right)$, and $R Z R \beta\left(\boldsymbol{E}, \boldsymbol{E}^{\prime}\right)$ in layer 4. The filled arrowheads point to the rostral limit of the caudal expression domain (outlining the visual plus parietal domain) of $I d 2$ in layer 5, Cadherin6 in low layers, and COUP-TF1 in layer 4. In $\boldsymbol{D}$ and $\boldsymbol{D}^{\prime}$, the open arrowheads and the open arrows point to the rostral and caudal limits of the faint expression of EphA7 in the caudal and rostral cortex, respectively.

\section{Mild alterations of corticofugal projections in early postnatal Pax6cKO brains}

We traced corticofugal projections from SS and $\mathrm{M}$ at early postnatal ages (P1-P12). DiI crystal placement into the SS cortex revealed a labeled fiber bundle that descended to the internal capsule (supplemental Fig. 2J, available at www. jneurosci.org as supplemental material). Interestingly, not all fibers followed the abnormal path. In some brains (P1-P3), a small fiber bundle descended lateral to the cell mass at the PSPB through the external capsule toward the ventral pallium (arrow in supplemental Fig. $2 J$, available at www.jneurosci.org as supplemental material). Despite the thick cell aggregates along the PSPB junction, the majority of corticothalamic are capable of crossing the boundary and reaching the correct target. Altered projections were also found ascending medially from cortical crystal placement site in the SS cortex in some, but not all, cases. After DiI placement into the SS cortex of P1 (supplemental Fig. $3 A-F$, available at www.jneurosci.org as supplemental material) and P2 (supplemental Fig. 2G-P, available at www. jneurosci.org as supplemental material) brains, labeled fiber bundles could be followed toward the pial surface in the Pax6cKO (arrow in supplemental Fig. 3G, available at www.jneurosci.org as supplemental material) but not in the control cortex (data not shown). These labeled fibers avoid the cell aggregates in the white matter (supplemental Fig. 2D, available at www.jneurosci.org as supplemental material) and enter into the dorsomedial cortex. Such abnormalities were not observed at later (P10) stages.

It should be emphasized that the axonal trajectory and areal specificity appears to be generally preserved in the Pax6cKO: the corticofugal bundle of fibers from $\mathrm{M}$ and SS area follow a similar trajectory in the mutant and control brains (Fig. 8). The Vi and $\mathrm{M}$ cortical areas develop projections to the spinal cord and to the superior colliculus during the development of the layer 5 projections (Luo and O'Leary, 2005). At P10, we could observe transient axonal branches from motor cortices (similar to the one observed from visual cortex) toward the superior colliculus (SC), and we could follow fibers labeled from Vi to the spinal cord (Fig. 8). Toward the first postnatal week, the projections from $\mathrm{Vi}$ to the superior colliculus and the projections from $\mathrm{M}$ to the spinal cord get stabilized, whereas the transient projections from $\mathrm{M}$ to superior colliculus and from $\mathrm{Vi}$ to spinal 
Table 1. Quantification of proportional length of neocortical domains in the presumptive visual area in Pax6cK0 and control mice at P10

\begin{tabular}{|c|c|c|c|c|c|c|c|c|c|c|c|c|c|c|c|}
\hline \multirow[b]{2}{*}{ Genotypes } & \multicolumn{3}{|l|}{ Id2 } & \multicolumn{3}{|l|}{ Cdh6 } & \multicolumn{3}{|l|}{ CoupTf } & \multicolumn{3}{|l|}{$R z R ß$} & \multicolumn{3}{|c|}{ Mean of all markers } \\
\hline & NCX & Domain & Ratio & NCX & Domain & Ratio & NCX & Domain & Ratio & NCX & Domain & Ratio & NCX & Domain & Ratio \\
\hline WT $n$ & 6 & 6 & 6 & 6 & 6 & & 6 & 6 & 6 & 4 & 4 & & 22 & 22 & 22 \\
\hline Mean & 17.48 & 3.43 & 0.20 & 17.13 & 3.37 & 0.20 & 17.43 & 3.50 & 0.20 & 16.75 & 3.65 & 0.22 & 17.24 & 3.39 & 0.20 \\
\hline $\pm S D$ & 0.18 & 1.1 & 0.06 & 0.31 & 1.03 & 0.06 & 0.36 & 0.58 & 0.03 & 0.29 & 1.17 & 0.07 & 0.22 & 0.84 & 0.05 \\
\hline Pax6cKOn & 5 & 5 & 5 & 4 & 4 & 4 & 5 & 4 & 4 & 4 & 3 & 3 & 18 & 16 & 16 \\
\hline Mean & 13.6 & 4.55 & 0.34 & 13 & 3.66 & 0.27 & 13.2 & 3.83 & 0.29 & 13.13 & 3.9 & 0.3 & 13.13 & 3.99 & 0.3 \\
\hline $\pm S D$ & 0.42 & 0.71 & 0.04 & 0.5 & 0.3 & 0.02 & 0.45 & 0.45 & 0.04 & 0.25 & 0.66 & 0.06 & 0.42 & 0.34 & 0.03 \\
\hline$p<$ & 0.0001 & 0.05 & 0.005 & 0.0001 & 0.054 & 0.05 & 0.0001 & * & 0.05 & 0.0001 & 0.05 & 0.005 & 0.0001 & 0.05 & 0.01 \\
\hline
\end{tabular}

Proportional quantification of distinct cortical domains based on the regional expression of cortical areal markers in the Pax $6 \mathrm{~K} 0$ and control brains. The title of the table indicates the analyzed cortical domain and the regional markers used in the performed radioactive in situ hybridization assays (see also supplemental Fig. 1, available at www.jneurosci.org as supplemental material). The ratio between the length of each expression domain of the markers used and the length of the NCX in the corresponding sections was calculated individually for the three levels of sectioning (levels $3-5$ indicated in the schema in Fig. 3 ) of control and Pax6cKO brains. The last column contains the averaged values of the estimated ratios for the markers used. The $p$ values relative to observed differences are listed below each column. Results are synthesized in histograms in Figure $3 F-1$.

*Not statistically proven differences $(p>0.05)$ between the compared groups by two-tailed, unpaired Student's $t$ test.

Table 2. Quantification of proportional length of neocortical domains in the occipital + parietal cortex (up to SS/M boundary) and in the occipital and part of the parietal cortex in Pax6cK0 and control mice at P10

\begin{tabular}{|c|c|c|c|c|c|c|c|c|c|c|c|c|c|c|c|}
\hline \multirow[b]{2}{*}{ Genotypes } & \multicolumn{3}{|l|}{ Id2 } & \multicolumn{3}{|l|}{ Cdh6 } & \multicolumn{3}{|l|}{ Couptf } & \multicolumn{3}{|c|}{ Mean of all markers } & \multicolumn{3}{|l|}{ EphA7 } \\
\hline & NCX & Domain & Ratio & NCX & Domain & Ratio & NCX & Domain & Ratio & NCX & Domain & Ratio & $N C X$ & Domain & Ratio \\
\hline WT $n$ & 6 & 5 & 5 & 6 & 5 & 5 & 4 & 4 & 4 & 16 & 14 & 14 & 6 & 6 & 6 \\
\hline Mean & 17.48 & 10.94 & 0.62 & 17.13 & 12.02 & 0.7 & 17.45 & 12.83 & 0.74 & 17.33 & 11.69 & 0.67 & 17.38 & 6.3 & 0.36 \\
\hline Pax6cKOn & 4 & 4 & 4 & 5 & 5 & 5 & 2 & 2 & 2 & 11 & 11 & 11 & 6 & 6 & 6 \\
\hline Mean & 13.6 & 11.25 & 0.83 & 13 & 11.5 & 0.89 & 13.5 & 9.5 & 0.7 & 13.27 & 11.17 & 0.84 & 12.67 & 6.17 & 0.49 \\
\hline $\pm S D$ & 0.42 & 0.5 & 0.05 & 0.5 & 0 & 0.03 & 0 & 0 & 0 & 0.41 & 0.49 & 0.06 & 0.52 & 0.41 & 0.04 \\
\hline
\end{tabular}

Proportional quantification of distinct cortical domains based on the regional expression of cortical areal markers in the Pax 6 K 0 and control brains. The title of the table indicates the analyzed cortical domain and the regional markers used in the performed radioactive in situ hybridization assays (see also supplemental Fig. 1, available at www.jneurosci.org as supplemental material). The ratio between the length of each expression domain of the markers used and the length of the NCX in the corresponding sections was calculated individually for the three levels of sectioning (levels $3-5$ indicated in the schema in Fig. 3) of control and Pax6cKO brains. The last column contains the averaged values of the estimated ratios for the markers used. The $p$ values relative to observed differences are listed below each column. Results are synthesized in histograms in Figure $3 F-1$.

*Not statistically proven differences ( $p>0.05$ ) between the compared groups by two-tailed, unpaired Student's $t$ test.

Table 3. Quantification of proportional length of neocortical domains in the frontoorbital/motor area in Pax6cK0 and control mice at P10

\begin{tabular}{|c|c|c|c|c|c|c|c|c|c|c|c|c|}
\hline \multirow[b]{2}{*}{ Genotypes } & \multicolumn{3}{|l|}{$\operatorname{ld} 2(-)$} & \multicolumn{3}{|l|}{ Cdh6(-) } & \multicolumn{3}{|c|}{ EphA7(+) } & \multicolumn{3}{|c|}{ Mean of all markers } \\
\hline & NCX & Domain & Ratio & NCX & Domain & Ratio & $\mathrm{NCX}$ & Domain & Ratio & NCX & Domain & Ratio \\
\hline WT $n$ & 4 & 4 & 4 & 5 & 5 & 5 & 6 & 6 & 6 & 15 & 15 & 15 \\
\hline Mean & 17.53 & 6.48 & 0.37 & 17.22 & 5.2 & 0.3 & 17.38 & 5.67 & 0.33 & 17.38 & 5.69 & 0.33 \\
\hline Pax6cKOn & 5 & 4 & 4 & 5 & 5 & 5 & 6 & 6 & 6 & 16 & 15 & 15 \\
\hline Mean & 13.6 & 2.38 & 0.14 & 13 & 1.5 & 0.11 & 12.67 & 2.13 & 0.17 & 13.1 & 1.95 & 0.15 \\
\hline $\pm S D$ & 0.42 & 0.75 & 0.09 & 0.5 & 0.5 & 0.03 & 0.52 & 0.29 & 0.02 & 0.37 & 0.36 & 0.02 \\
\hline
\end{tabular}

Proportional quantification of distinct cortical domains based on the regional expression of cortical areal markers in the Pax 6 K $\mathrm{O}$ and control brains. The title of the table indicates the analyzed cortical domain and the regional markers used in the performed radioactive in situ hybridization assays (see also supplemental Fig. 1, available at www.jneurosci.org as supplemental material). The ratio between the length of each expression domain of the markers used and the length of the NCX in the corresponding sections was calculated individually for the three levels of sectioning (levels $3-5$ indicated in the schema in Fig. 3) of control and Pax 6 cKO brains. The last column contains the averaged values of the estimated ratios for the markers used. The $p$ values relative to observed differences are listed below each column. Results are synthesized in histograms in Figure $3 F-1$.

*Not statistically proven differences ( $p>0.05$ ) between the compared groups by two-tailed, unpaired Student's $t$ test.

cord get pruned (Luo and O'Leary, 2005). In the Pax6cKO, branches from $\mathrm{M}$ to superior colliculus and Vi toward the spinal cord appeared stronger compared with WT, suggesting that their pruning was delayed by age P10 (Fig. 8).

\section{Discussion}

Evidence suggest that altering the graded expression of transcription factors (e.g., Emx2, COUP-TF1, Pax6, and Sp8) at early stages of cortical development changes cortical gene expression gradients, cytoarchitecture, and thalamocortical connectivity in parallel according to the "cooperative concentration model" (O'Leary et al., 2007, O'Leary and Sahara, 2008). Considerable support is found for such role for Sp8, Emx2, and COUP-TF1 (O'Leary and Nakagawa, 2002; Grove and Fukuchi-Shimogori, 2003; Sur and Rubenstein, 2005; Rash and Grove, 2006; Mallamaci and Stoykova, 2007), but the involvement of Pax6 has been less clear. Overexpression of Pax6 in cortex of transgenic mice had little effect on areal targeting of thalamocortical connectivity (Manuel et al., 2007), and our current findings indicate, that although the cortex of the Pax $6 c \mathrm{KO}$ mice is molecularly caudalized, the thalamocortical connectivity remains unchanged.

Here we show, based on expression patterns of regional specific markers, that the presumptive borders between the Vi/SS and SS/M areas are shifted rostrally in the postnatal Pax6cKO as expected from previous results for Sey/Sey embryonic cortex (Bishop et al., 2000, 2002; Muzio et al., 2002). Pax6 is an intrinsic determinant of the radial glia, playing a role in regulation of progenitor cell cycle (Götz et al., 1998; Estivill-Torrus et al., 2002). Absence of Pax6 in cortical progenitors is shown to accelerate withdrawal from the mitotic cycle, leading to a premature neuronal differentiation of the $\mathrm{Pax}^{-1-}$ progenitors at early 

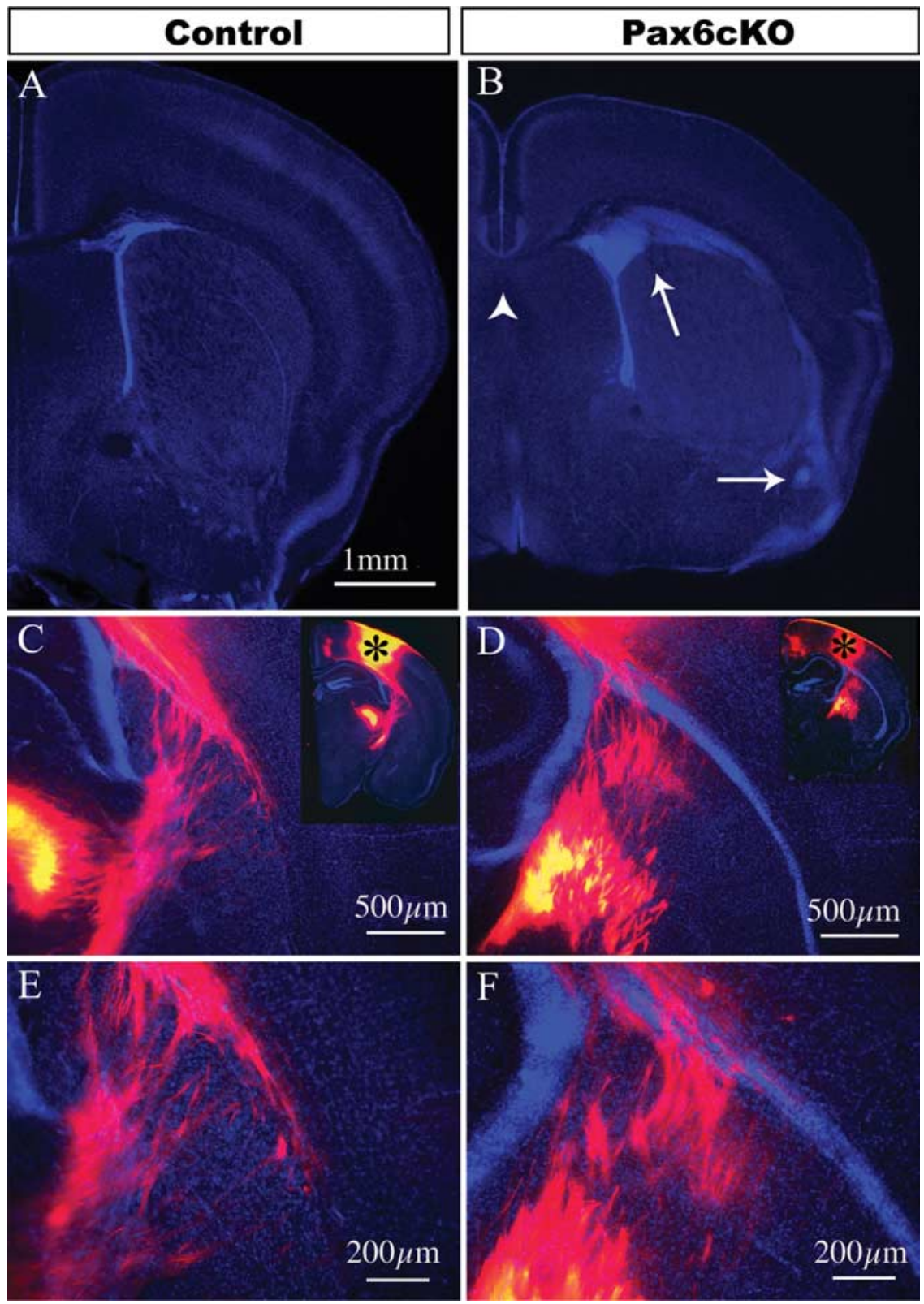

Figure 5. Corticothalamic and thalamocortical fibers cross the corticostriatal junction despite dense cell masses in the Pax6cKO. Coronal sections from the control and Pax6CKO brains stained for bisbenzimide. $A, B, A$ dense cell mass is present at the corticostriatal junction, extending from the intermediate zone of the cortex to beneath the lateral cortex and amygdala (arrows). C $\boldsymbol{F}$, Carbocyanine dye tracing from the anterior somatosensory cortex (insets in $\mathbf{C}$ and $\boldsymbol{D}$ depict the crystal placement sites) revealed that, despite the cell mass, the fiber bundles labeled from the cortex cross the corticostriatal junction. The fiber bundles could be followed to the correct thalamic nuclei $(\boldsymbol{C}-\boldsymbol{F})$ as well as the other subcortical targets.

stages (Estivill-Torrus et al., 2002; Quinn et al., 2007). This leads to a reduction of the early progenitor pool and diminishing of the rostral cortex that parallels the graded rostrolateral ${ }^{\text {high }}$ to caudomedial ${ }^{\text {low }}$ expression of Pax6. Indeed, a severe suppression of the entire rostrolateral domain of the telencephalon including the motor area was found in E10.5 Sey/Sey embryos (Muzio et al., 2002). In contrast, the relative length of the retrosplenial cortex (judged by the restricted expression pattern of $I d 2$ ) was augmented in the Pax6cKO. This may reflect an early patterning defect in Pax6 deficiency, causing a medial-to-lateral expansion of the Wnt3a expression domain, a factor regulating cellular growth (Muzio et al., 2002; Grove and Fukuchi-Shimogori, 2003). Cortex-specific ablation of COUP-TF1 function causes a massive expansion of the motor area associated with a slight increase of the Pax6 expression (Armentano et al., 2007). Notably, increased COUP-TF1 dosage alters molecular properties of the rostral cortex and inhibits both the Pax6 and Emx2 expression (Faedo et al., 2008). Similarly to Pax6, COUP-TF1 regulates progenitor proliferation and neurogenesis. However, no data show a direct interaction between Pax6 and COUP-TF1, and the available results support the view that cortical patterning is controlled by Pax6- and COUP-TF1-dependent pathways acting in parallel (O'Leary et al., 2007; Faedo et al., 2008). Thus, the present evidence suggests that the major role of Pax6 in cortical arealization involves cell growth control at the onset of neurogenesis.

We found in postnatal Pax6cKO that, although caudal NCX area (Vi, Par) expands, it retains thalamocortical connections appropriate to its relative position on the cortical sheet, and, although the FrO/M area is severely diminished as revealed by gene expression patterns, the areal topography of the labeled TCAs from the motor cortex in the Pax $6 c K O$ remains similar to the controls. These results are congruent with the PAX77 $Y A C$ transgenic mice, carrying several copies of human PAX6, and also show normal thalamocortical projections (Manuel et al., 2007). Recent evidence suggests that COUPTF1 endows positional specification that controls the areal size and position as well as targeting of area-specific thalamocortical projections (Armentano et al., 2007). Accordingly, the expanded rostral expression of COUP-TF1 in the Pax6cKO could contribute to the preservation of normal TCA connectivity of the enlarged parietal domain in the mutant. Dissociation between the cortical region-specific gene expression and the thalamocortical connectivity has been observed in other mutants as well. For example, the Ebf1 and Dlx1/2 double KO mice demonstrate a thalamocortical shift without any shift its cortical gene expression (Garel et al., 2002, 2003). The Mash1 and Gbx2 KO mice also display a shift in early thalamocortical projections that do not reach the cortex, whereas the embryonic cortical gene expression patterns remain not affected (Miyashita-Lin et al., 1999; Nakagawa et al., 1999). Similar to Pax6cKO mice, Fgf8 hypomorphic mutants display molecular caudalization of the rostral cortex with apparently normal thalamocortical connectivity (Garel et al., 2003). Together with our new findings in $P a x 6 c K O$, these results support the view that molecular regionalization and thalamic connectivity are possibly not strictly interdependent processes (Garel et al., 2002).

The TFs Pax6 and Sp8 have similar rostral ${ }^{\text {high }}$ to caudal ${ }^{\text {low }}$ expression gradients along the anteroposterior axis of the cortical primordium. Conditional inactivation of Sp8 in developing telencephalon causes a prominent caudalization of the molecular 

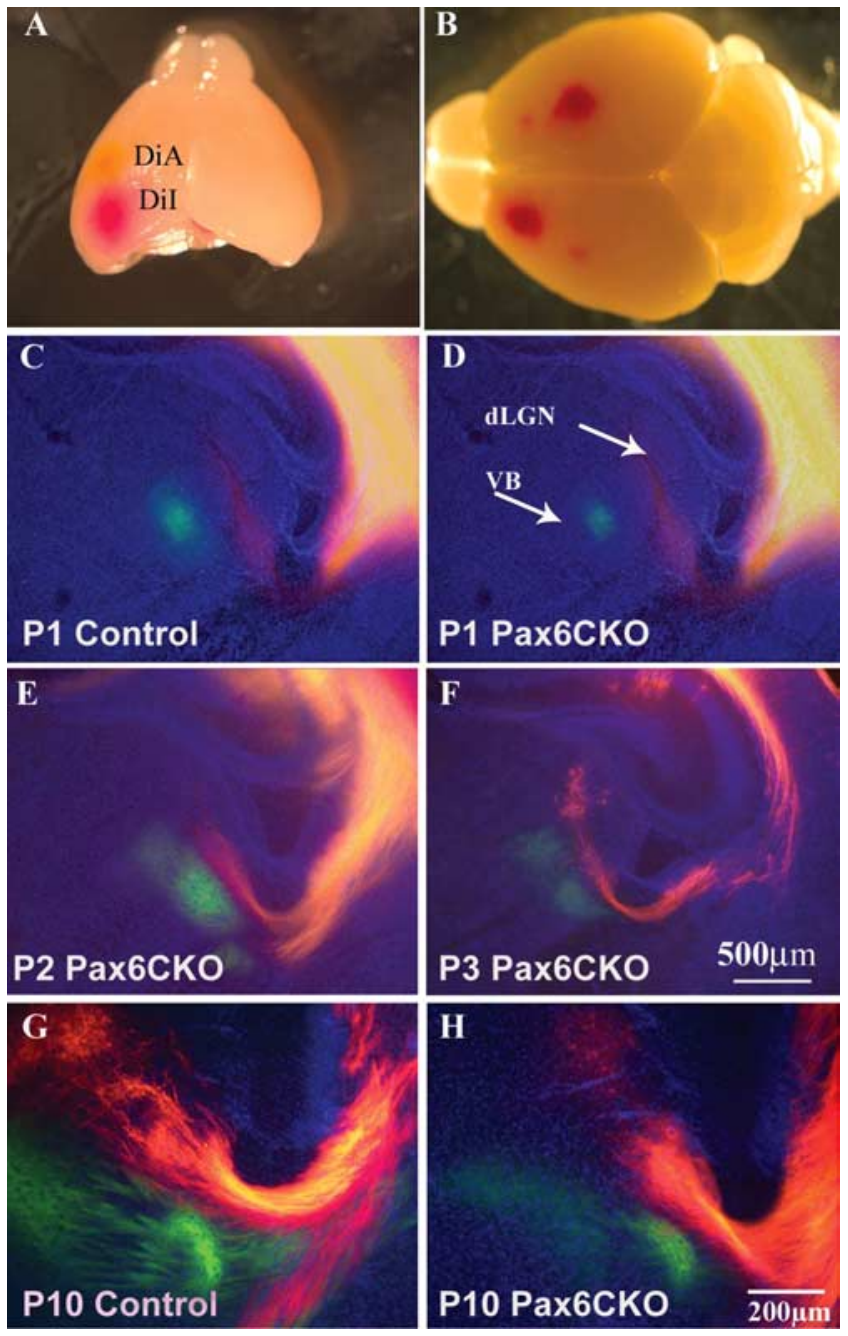

Figure 6. No difference in the topographic organization of the thalamocortical connectivity in the Pax6cKO and control mice. A, DiA and Dil were placed in the somatosensory and visual cortex, respectively, in the Pax6cKO and control P1, P2, P3, and P10 mice as indicated. $B$, DiA and Dil were also placed in the motor and somatosensory cortex at P10 control and Pax6cKO. Backlabeled cells in the dLGN (orange/red) and VB (green) can be observed together with the labeled fiber bundles descending from the cortex through the internal capsule in both control and Pax6cK0 brains at P1-P3 $(\boldsymbol{C}-\boldsymbol{F})$ and P10 $(\boldsymbol{G}, \boldsymbol{H})$. Fibers and back-labeled cells were found in the VA and VB in the control and Pax6cKO brains (data not shown). No obvious topographical shift of the thalamocortical projection was observed in the Pax6cKO.

properties of the cortical neuroepithelium, including enhancement of Emx2 and reciprocal inhibition of Pax6 expression, together with ectopic rostral extension of the caudal expression territories of COUP-TF1 and Id2 (Zembrzycki et al., 2007). In addition, the disturbance of the molecular patterning of the $S p 8^{-/-}$cortex was accompanied by defects of the TCA targeting, suggesting a partial change in the cortical identity (SS into Vi). Sp8 regulates the expression of $\mathrm{F} \& 8$, a powerful modulator of the cortical size that is secreted by the anterior neural reach (Storm et al., 2006; Zembrzycki et al., 2007). Interestingly, Pax6 and Fgf8 do not to seem to interact (Grove, 2002; Garel et al., 2003). A plausible conclusion remains to be that $\mathrm{Sp} 8$, but not Pax6, has a decisive role in endowing the early anteroposterior areal patterning of the cortex.

The Emx1-Cre line is currently the most appropriate genetic tool to achieve cortex-specific conditional genetic ablation used in analysis of thalamocortical connectivity (Armentano et al., 2007). We acknowledge the possibility that, although the Emx1-
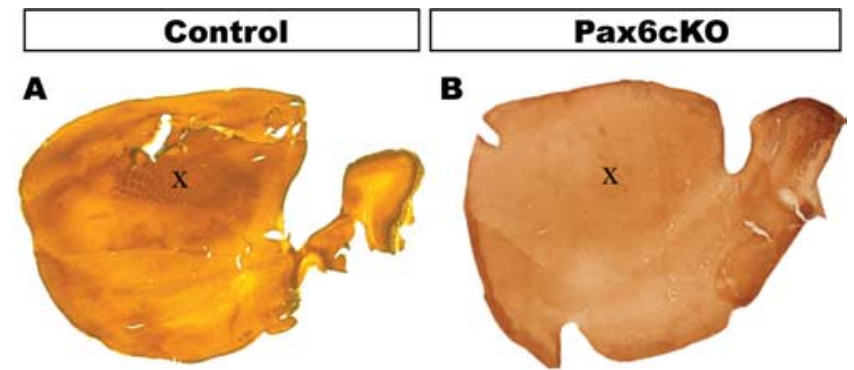

C

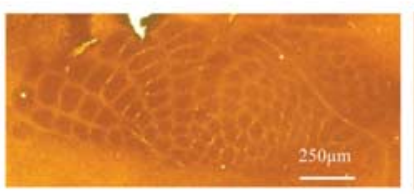

D
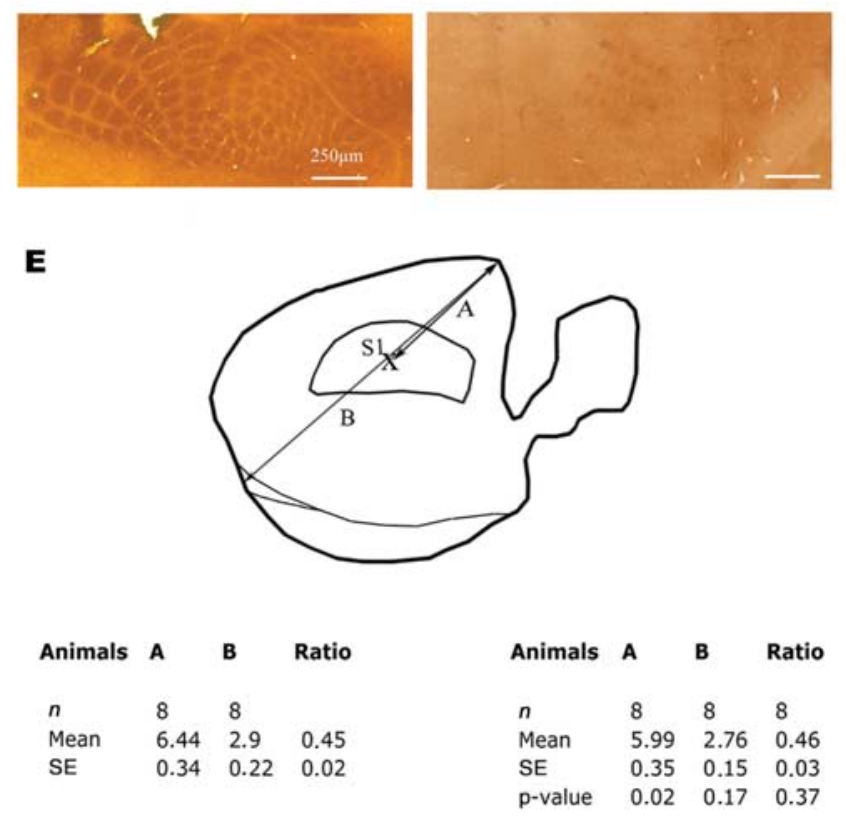

Figure 7. Thalamocortical projections assume normal periphery-related pattern with normal position in the barrel cortex of the Pax6cK0. Flat-mount preparations from control and Pax6cKO brains stained for cytochrome-oxidase to visualize the position and organization of the barrel field in SS at P10. C and $D$ are high-magnification images taken from $A$ and $\boldsymbol{B}$ showing the presence of barrel fields in both genotypes. $\boldsymbol{B}$ demonstrates the presence of the overall periphery-related pattern, although the individual components are less well defined in the barrel field of the SS cortex in the Pax6cKO cortex compared with control. Despite the reduced definition of individual components, the overall position of the periphery-related representation is not changed. The relative position of the barrel field in relation to the total length of the cerebral hemisphere was found similar in Pax6cK0 as in the control. $\boldsymbol{E}$, Measurements from the rostral pole to the center of the barrel field, as well as its proportion in relation to the total distance between the rostral and caudal pole, were calculated for mutant and control brains showing no statistical difference. Scale bar, $200 \mu \mathrm{m}$.

Cre line initiates at $\mathrm{E} 9.5$ and reaches full Cre recombinase activity at E12.5 (Gorski et al., 2002; Li et al., 2003; our own observations), Pax6 function might not have been completely abolished during the earliest stages of corticogenesis. However, calretinin immunohistochemistry on sections of E15.5 brains revealed that only few positive cells were present at the presumptive subplate position in the mutant cortex (data not shown), indicating subplate alterations in the Pax6cKO.

The arrival and ingrowth of the thalamic projections were revealed by DiI/DiA tracing, and the normal position of the characteristic periphery-related clustering of the thalamocortical projections in the primary somatosensory cortex was revealed by the cytochrome-oxidase activity in the Pax6cKO brain. Thalamocortical axons invade, branch, and assume a periphery-related pattern in SS of the Pax6cKO despite severe depletion of layer 4 and supragranular layers. Although this pattern is reduced and less 


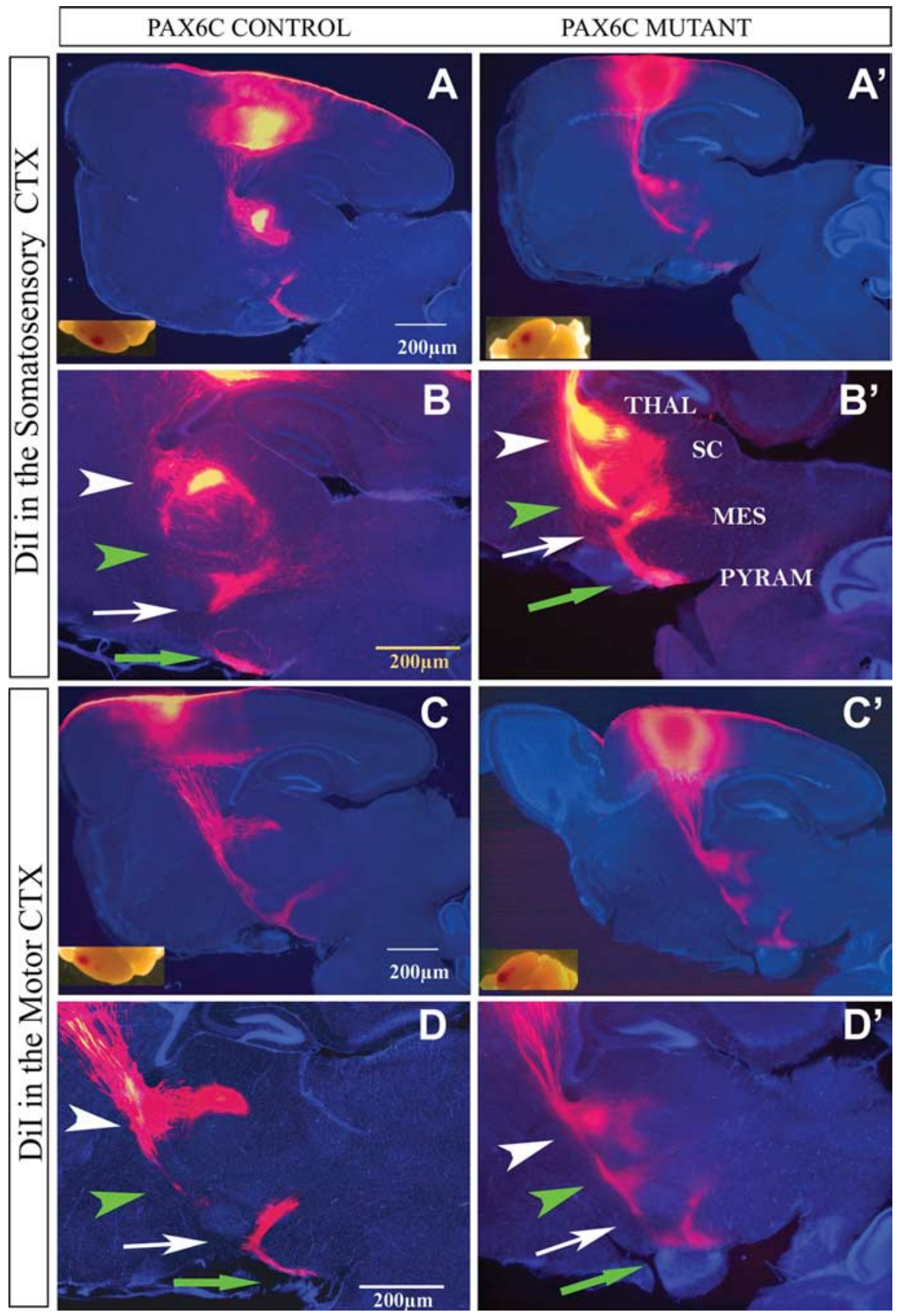

Figure 8. Major axonal trajectories from the somatosensory and motor cortex are preserved in the Pax6cKO brain. Dil placement into the SS and $M$ cortex labeled axon bundles that comprised the corticothalamic, thalamocortical, corticopontine, corticotectal, and corticospinal axons. These could be followed extending toward the cerebral peduncle (green arrow) branching off at the ventroposterior or ventroanterior nucleus of the thalamus (THAL; white arrowheads), SC (green arrowheads), and mesencephalon (MES; white arrows). Note that the branch from M or SS cortex toward the SC appears much more prominent in the Pax6cK0 brain (green arrowheads in $\boldsymbol{B}, \boldsymbol{B}^{\prime}, \boldsymbol{D}^{\prime} \boldsymbol{D}^{\prime}$ ) than in control.

clearly defined in the Pax6cKO, it is still centered in a similar position to the normal brains. We observed no clustering of layer 4 cells (after Nissl or bisbenzimide staining) at the site of cytochrome-oxidase clustering, which suggests that TCA projections assume periphery-related patterning but it is unable to impose barrel (cytoarchitectonic) differentiation on the cortex. The mechanisms responsible for the establishment of peripheryrelated TCA pattern and the cytoarchitecture are believed to be presynaptic and postsynaptic, respectively (Molnár and Hannan, 2000).

Analyses of the TCA connectivity in the Sey/Sey suggested an involvement of Pax6 in mechanisms of crossing the PSPB (Hevner et al., 2002; Jones et al., 2002). However, although in the conventional Pax6KO brain the TCA projections could not cross the PSPB (Jones et al., 2002; Kroll and O'Leary, 2005), in the Pax6cKO the majority of both TCA and CTA projections do cross this region. A small fraction of the early corticofugal projections descended through the external capsule lateral to the cell mass along the PSPB to target the ventral pallium, but it was much less severe as in the conventional Pax6KO (Jones et al., 2002). Thus, the massive accumulation of cellular masses at the PSPB of Sey/Sey cortex seems to hamper axonal navigation (LópezBendito and Molnár, 2003).

Our tracing experiments in Pax6cKO suggest that, although the basic layout of the area specific cortical connectivity is preserved, the area-specific pruning of corticofugal output was slightly altered. Pruning of exuberant neuronal connections in response to local cues is a widespread mechanism to develop diversity and specificity of axonal connections in the adult vertebrate brain through which early projections are refined or redirected (Luo and O'Leary, 2005). We found that, although corticofugal connectivity develops normally, retraction of the transient projection of L5 neurons (from the $\mathrm{M}$ and SS cortex to SC) seem to be abnormal in the juvenile $P a x 6 c K O$ forebrain. Presently, we do not know whether this abnormality persists in the adult brain, and additional experiments are needed to elucidate the potential role of Pax6 in the refinement of area-specific L5 corticofugal projections.

In summary, our findings indicate that the gradient expression of Pax6 in the pallial progenitors does not have an intrinsic role in specification of cortical area identity and in establishment of the TCA and CTA connectivity. The availability of live Pax6-deficient mutants will help to better understand the involvement of Pax6 in genetic interactions specifying distinct aspects of mammalian corticogenesis.

\section{References}

Armentano M, Chou SJ, Tomassy GS, Leingärtner A, O'Leary DDM, Studer M (2007) COUPTFI regulates the balance of cortical patterning between frontal/motor and sensory areas. Nat Neurosci 10:1277-1286.

Ashery-Padan R, Marquardt T, Zhou X, Gruss P (2000) Pax6 activity in the lens primordium is required for lens formation and for correct placement of a single retina in the eye. Genes Dev 14:2701-2711.

Bishop KM, Goudreau G, O'Leary DD (2000) Regulation of area identity in the mammalian neocortex by Emx2 and Pax6. Science 288:344-349.

Bishop KM, Rubenstein JL, O'Leary DD (2002) Distinct actions of Emx1, Emx2, and Pax6 in regulating the specification of areas in the developing neocortex. J Neurosci 22:7627-7638.

Bishop KM, Garel S, Nakagawa Y, Rubenstein JL, O’Leary DDM (2003) Emxl and Emx2 cooperate to regulate cortical size, lamination, neuronal 
differentiation, development of cortical efferents, and thalamocortical pathfinding. J Comp Neurol 457:345-360.

Dehay C, Kennedy H (2007) Cell-cycle control and cortical development. Nat Rev Neurosci 8:438-450.

Estivill-Torrus G, Pearson H, van Heyningen V, Price DJ, Rashbass P (2002) Pax6 is required to regulate the cell cycle and the rate of progression from symmetrical to asymmetrical division in mammalian cortical progenitors. Development 129:455-466.

Faedo A, Tomassy GS, Ruan Y, Teichmann H, Krauss S, Pleasure SJ, Tsai MJ, Studer M, Rubenstein JL (2008) COUP-TF1 coordinates cortical patterning, neurogenesis, and laminar fate and modulates MAPK/ERK, AKT and $\beta$-catenin signaling. Cereb Cortex, in press.

Garel S, Yun K, Grosschedl R, Rubenstein JL (2002) The early topography of thalamocortical projections is shifted in Ebf1 and Dlx1/2 mutant mice. Development 129:5621-5634.

Garel S, Huffman KJ, Rubenstein JL (2003) Molecular regionalization of the neocortex is disrupted in Fgf8 hypomorphic mutants. Development 130:1903-1914.

Gorski JA, Talley T, Qiu M, Puelles L, Rubenstein JL, Jones KR (2002) Cortical excitatory neurons and glia, but not GABAergic neurons, are produced in the Emx1-expressing lineage. J Neurosci 22:6309-6314.

Grove E (2002) Generating the mammalian neocortical area map. Paper presented at Nature and Nurture in Brain Development, INMED Conference, La Ciotat, France, September.

Grove EA, Fukuchi-Shimogori T (2003) Generating the cerebral cortical area map. Annu Rev Neurosci 26:355-380.

Hevner RF, Miyashita-Lin E, Rubenstein JL (2002) Cortical and thalamic axon pathfinding defects in Tbr1, Gbx2, and Pax6 mutant mice: evidence that cortical and thalamic axons interact and guide each other. J Comp Neurol 447:8-17.

Hill RE, Favor J, Hogan BL, Ton CC, Saunders GF, Hanson IM, Prosser J, Jordan T, Hastie ND, van Heyningen V (1991) Mouse Small eye results from mutations in a paired-like homeobox-containing gene. Nature 354:522-525.

Huffman KJ, Garel S, Rubenstein JL (2004) Fgf8 regulates the development of intra-neocortical projections. J Neurosci 24:8917-8923.

Jones L, López-Bendito G, Gruss P, Stoykova A, Molnár Z (2002) Pax6 is required for the normal development of the forebrain axonal connections. Development 129:5041-5052.

Kroll TT, O'Leary DD (2005) Ventralized dorsal telencephalic progenitors in Pax6 mutant mice generate GABA interneurons of a lateral ganglionic eminence fate. Proc Natl Acad Sci U S A 102:7374-7379.

Li HS, Wang D, Shen Q, Schonemann MD, Gorski JA, Jones KR, Temple S, Jan LY, Jan YN (2003) Inactivation of Numb and Numblike in embryonic dorsal forebrain impairs neurogenesis and disrupts cortical morphogenesis. Neuron 40:1105-1118.

Liu Q, Dwyer ND, O'Leary DD (2000) Differential expression of COUPTFI, CHL1, and two novel genes in developing neocortex identified by differential display PCR. J Neurosci 20:7682-7690.

López-Bendito G, Molnár Z (2003) Thalamocortical development: how are we going to get there? Nat Rev Neurosci 4:276-289.

Luo L, O'Leary DD (2005) Axon retraction and degeneration in development and disease. Annu Rev Neurosci 28:127-156.

Mallamaci A, Stoykova A (2006) Gene networks controlling early cerebral cortex arealization. Eur J Neurosci 23:847-856.

Manuel M, Georgala PA, Carr CB, Chanas S, Kleinjan DA, Martynoga B, Mason JO, Molinek M, Pinson J, Pratt T, Quinn JC, Simpson TI, Tyas DA, van Heyningen V, West JD, Price DJ (2007) Controlled overexpression of Pax6 in vivo negatively autoregulates the Pax6 locus, causing cellautonomous defects of late cortical progenitor proliferation with little effect on cortical arealization. Development 134:545-555.

Miyashita-Lin EM, Hevner R, Wassarman KM, Martinez S, Rubenstein JL (1999) Early neocortical regionalization in the absence of thalamic innervation. Science 285:906-909.
Molnár Z, Hannan AJ (2000) Development of thalamocortical projections in normal and mutant mice. Results Probl Cell Differ 30:293-332.

Molnár Z, Knott GW, Blakemore C, Saunders NR (1998) Development of thalamocortical projections in the South American gray short-tailed opossum (Monodelphis domestica). J Comp Neurol 398:491-514.

Mori T, Wanaka A, Taguchi A, Matsumoto K, Tohyama M (1995) Localization of novel receptor tyrosine kinase genes of the eph family MDK1 and its splicing variant, in the developing mouse nervous system. Mol Brain Res 34:154-160.

Muzio L, DiBenedetto B, Stoykova A, Boncinelli E, Gruss P, Mallamaci A (2002) Emx2 and Pax6 control regionalization of the pre-neuronogenic cortical primordium. Cereb Cortex 12:129-139.

Nakagawa Y, Johnson JE, O’Leary DD (1999) Graded and areal expression patterns of regulatory genes and cadherins in embryonic neocortex independent of thalamocortical input. J Neurosci 19:10877-10885.

O'Leary DD (1989) Do cortical areas emerge from a protocortex? Trends Neurosci 12:400-406.

O'Leary DD, Nakagawa Y (2002) Patterning centers, regulatory genes and extrinsic mechanisms controlling arealization of the neocortex. Curr Opin Neurobiol 12:14-25.

O'Leary DD, Sahara S (2008) Genetic regulation of arealization of the neocortex. Curr Opin Neurobiol 18:90-100.

O'Leary DD, Schlaggar BL, Tuttle R (1994) Specification of neocortical areas and thalamocortical connections. Annu Rev Neurosci 17:419-439.

O'Leary DD, Chou SJ, Sahara S (2007) Area patterning of the mammalian cortex. Neuron 56:252-269.

Price DJ, Kennedy H, Dehay C, Zhou L, Mercier M, Jossin Y, Goffinet AM, Tissir F, Blakey D, Molnár Z (2006) The development of cortical connections. Eur J Neurosci 23:910-920.

Quinn JC, Molinek M, Martynoga BS, Zaki PA, Faedo A, Bulfone A, Hevner RF, West JD, Price DJ (2007) Pax6 controls cerebral cortical cell number by regulating exit from the cell cycle and specifies cortical cell identity by a cell autonomous mechanism. Dev Biol 302:50-65.

Rakic P (1988) Specification of cerebral cortical areas. Science 241:170-176.

Rash BG, Grove EA (2006) Area and layer patterning in the developing cerebral cortex. Curr Opin Neurobiol 16:25-34.

Rubenstein JL, Anderson S, Shi L, Miyashita-Lin E, Bulfone A, Hevner R (1999) Genetic control of cortical regionalization and connectivity. Cereb Cortex 9:524-532.

Storm EE, Garel S, Borello U, Hebert JM, Martinez S, McConnell SK, Martin GR, Rubenstein JL (2006) Dose-dependent functions of FGF8 in regulating telencephalic patterning centers. Development 133:1831-1844.

Stoykova A, Gruss P (1994) Roles of Pax-genes in developing and adult brain as suggested by expression patterns. J Neurosci 14:1395-1412.

Stoykova A, Fritsch R, Walther C, Gruss P (1996) Forebrain patterning defects in Small eye mutant mice. Development 122:3453-3465.

Stoykova A, Treichel D, Hallonet M, Gruss P (2000) Pax6 modulates the dorsoventral patterning of the mammalian telencephalon. J Neurosci 20:8042-8050.

Sur M, Rubenstein JL (2005) Patterning and plasticity of the cerebral cortex. Science 310:805-810.

Toresson H, Potter SS, Campbell K (2000) Genetic control of dorsal-ventral identity in the telencephalon: opposing roles for Pax6 and Gsh2. Development 127:4361-4371.

Warren N, Price DJ (1997) Roles of Pax-6 in murine diencephalic development. Development 124:1573-1582.

Wong-Riley MT (1979) Changes in the visual system of monocularly sutured or enucleated cats demonstrable with cytochrome-oxidase histochemistry. Brain Res 171:11-28.

Yun K, Potter S, Rubenstein JL (2001) Gsh2 and Pax6 play complementary roles in dorsoventral patterning of the mammalian telencephalon. Development 128:193-205.

Zembrzycki A, Griesel G, Stoykova A, Mansouri A (2007) Genetic interplay between the transcription factors Sp8 and Emx2 in the patterning of the forebrain. Neural Develop 2:8. 